\title{
Medication for Opioid Use Disorder Service Provision and Telephone Counseling: A Concurrent Mixed-Methods Approach
}

\author{
Rosemarie Martin ${ }^{1, *,+}$, Augustine W. Kang ${ }^{1,+}{ }^{\mathbb{D}}$, Audrey A. DeBritz ${ }^{1}$, Mary R. Walton ${ }^{2}$, Ariel Hoadley ${ }^{3}$, \\ Courtney DelaCuesta ${ }^{1}$ and Linda Hurley ${ }^{2}$ \\ 1 Center for Alcohol and Addiction Studies, School of Public Health, Brown University, \\ Providence, RI 02903, USA; augustine_kang@brown.edu (A.W.K.); audrey_debritz@brown.edu (A.A.D.); \\ courtney_delacuesta@brown.edu (C.D.) \\ 2 CODAC Behavioral Healthcare Inc., Cranston, RI 02910, USA; mwalton@codacinc.org (M.R.W.); \\ lhurley@codacinc.org (L.H.) \\ 3 College of Public Health, Temple University, Philadelphia, PA 19122, USA; ariel_hoadley@brown.edu \\ * Correspondence: rosemarie_martin@brown.edu; Tel.: +1-(401)-863-6656 \\ + Denotes equal authorship.
}

\section{check for}

updates

Citation: Martin, R.; Kang, A.W.; DeBritz, A.A.; Walton, M.R.; Hoadley,

A.; DelaCuesta, C.; Hurley, L.

Medication for Opioid Use Disorder Service Provision and Telephone Counseling: A Concurrent Mixed-Methods Approach. Int. J. Environ. Res. Public Health 2021, 18, 6163. https://doi.org/10.3390/ ijerph18116163

Academic Editor: Paul B. Tchounwou

Received: 11 May 2021

Accepted: 4 June 2021

Published: 7 June 2021

Publisher's Note: MDPI stays neutra with regard to jurisdictional claims in published maps and institutional affiliations.

Copyright: (C) 2021 by the authors Licensee MDPI, Basel, Switzerland. This article is an open access article distributed under the terms and conditions of the Creative Commons Attribution (CC BY) license (https:// creativecommons.org/licenses/by/ $4.0 /)$

\begin{abstract}
Using quantitative and qualitative evidence, this study triangulates counselors' perspectives on the use of telemedicine in the context of Opioid Use Disorder (OUD) treatment. A concurrent mixed-methods design examined counselors' experiences with telephone counseling during the COVID-19 pandemic. $\mathrm{N}=42$ counselors who provided OUD counseling services completed a closeended, quantitative survey examining their experiences in addressing clients' anxiety, depression, anger, substance use, therapeutic relationship, and substance use recovery using telephone counseling. The survey also assessed comfort, convenience, and satisfaction with telephone counseling. Counselors also completed open-ended responses examining satisfaction, convenience, relationship with patients, substance use, and general feedback with telephone counseling. The synthesis of quantitative and qualitative evidence indicated that a majority of counselors had positive experiences with using telephone counseling to provide services to clients undergoing OUD treatment. Convenience, greater access to clients, and flexibility were among the reasons cited for their positive experience. However, counselors also expressed that the telephone counseling was impersonal, and that some clients may have difficulties accessing appropriate technology for telehealth adoption. Findings suggest that further research with counselors is needed to identify the key elements of an effective integration of telephone counseling with traditional in-person treatment approaches in the post-pandemic era.
\end{abstract}

Keywords: telehealth services; medication for opioid use disorder; needs assessment; counselors

\section{Introduction}

The opioid and COVID-19 epidemics have collectively precipitated an increase in opioid-related mortality in 2020 [1]. More than 3500 Emergency Departments (ED) in the United States reported that opioid overdoses consistently increased in 2020 compared to 2019 [2]. Prior to COVID-19, strict state and federal regulations and laws (in the United States) such as The Ryan Haight Act of 2008, the Drug Addiction Treatment Act of 2000, and 42 CFR 8 for opioid treatment programs (OTPs) enforced by the Substance Abuse and Mental Health Service Administration and Drug Enforcement Agency made opioid treatment difficult, time consuming, and costly for patients to access and receive medication and care. These regulations include restrictions on prescribing, dispensing, and limiting take-home medication for opioid use disorder (MOUD), as well as mandated face-to-face medical and clinical encounters to initiate and maintain MOUD [3-6]. COVID-19 brought about relaxations in laws and regulations, and policies materialized to reduce barriers to 
treatment reducing financial and administrative obstacles such as prior authorizations, copays, and licensing requirements, loosening of take-home MOUD in OTPs; one significant modification was the expansion of telehealth services in opioid use disorder (OUD) treatment. In the final week of March 2020, at the onset of the pandemic, the use of telehealth increased by $154 \%$ in the US compared to the same week in 2019 [7].

Behavioral healthcare service providers had to rapidly shift, essentially immediately, to offer virtual services in a way that safeguarded minimal service disruption for individuals in care while having to take on the rising number of new patients remotely [8-10].

Telehealth services increase patient access, adherence, and retention in treatment while yielding equivalent outcomes to in-person care [11-14]. However, rates of telehealth services provision and / or uptake for substance use disorder (SUD) were low before COVID19 [15]. A systematic review reported that telemedicine-based provision of counseling in SUD was feasible and effective, and a randomized control trial of therapy demonstrated lower attrition among participants receiving telehealth versus in-person care [16,17]. For OUD treatment specifically, some evidence indicates similar rates of counseling attendance, drug-positive urinalysis results, and retention in treatment with telehealth versus in-personbased provision of services $[18,19]$.

While providers are central in building an effective therapeutic relationship, limited literature exists that examines counselor satisfaction or perception of the therapeutic alliance, especially in the context of SUD treatment [20]. A recent survey examining provider satisfaction and telehealth experiences with outpatient mental health treatment providers (including psychiatrists and counselors) reported that providers were largely satisfied with telehealth, but may face challenges with caring for clients with psychiatric comorbidities and those with high symptom severity [21]. In addition, studies have also reported that providers were concerned with security, confidentiality, and technological issues with the use of telemedicine [22,23]. Providers should be cautious when managing patient health information in the context of telemedicine and pay special attention to patient information protections [24]. Other provider apprehensions were unsuitability for specific patients, particularly high-risk suicidal patients [25].

Understanding the experiences of providers is integral to informing the post-pandemic integration of telemedicine in the care provision model for OUD treatment. There are gaps in research regarding providers' perspectives on the use of telemedicine, particularly in the context of OUD treatment and via the format of telephone counseling. To gain insight into providers' perspectives on the use of telemedicine for OUD for the purpose of informing post-pandemic policies and care practices, this study aims to both quantitatively and qualitatively examine counselors' experiences with telephone counseling in the context of OUD treatment provision during the COVID-19 pandemic.

\section{Materials and Methods}

\subsection{Sample and Data Collection}

The current study analyzed data from a survey conducted by CODAC Behavioral Healthcare (Cranston, RI, USA) for a larger quality improvement project to assess counselor experience with telemedicine in the context of COVID-19 risk mitigation. The survey examined the experiences of counselors from seven Opioid Treatment Program (OTP) clinics across Rhode Island who participated in provision of telephone counseling. These counselors provided OUD counseling services at least once a month to their clients. Counselors completed a web-based survey between July and November 2020, and were entered into a raffle for a $\$ 25 \mathrm{gift}$ card. The CODAC research oversight committee reviewed and approved the project.

$\mathrm{N}=42$ counselors completed the online survey which contained 3-point (Less $=1$, The Same $=2$, and More = 3) and 5-point (Very Dissatisfied = 1 and Very Satisfied = 5) Likert-scale questions and open-ended responses. A total of nine Likert-scale questions examined: (1) Anxiety, (2) depression, (3) anger, (4) substance use, (5) recovery, (6) comfort, (7) convenience, (8) relationship with patients, and (9) overall satisfaction compared to face 
to face counseling. For example, the anxiety question was phrased as such, "How anxiety is addressed in telephone counseling sessions compared to face to face". Open-ended responses queried counselors' experiences with telephone counseling in the following five categories: Satisfaction, convenience, relationship with patients, substance use and recovery, and general feedback. Both the quantitative and qualitative data were collected concurrently.

\subsection{Concurrent Mixed-Methods Analysis Approach}

A concurrent mixed-methods analysis approach was used to analyze the study data [26]. While the quantitative data provides a numerical representation of the study variables (i.e., anxiety and depression), qualitative data additionally provides background and context to those variables by identifying themes and triangulating quantitative findings. This approach provides a comprehensive understanding of the counselors' experiences with telephone counseling.

In terms of qualitative analysis, the five open-ended response questions were coded using an inductive thematic analysis approach. A codebook was created by two independent coders (J.D. and R.U.); they read the counselors' open-ended responses and created preliminary codes. A third rater (A.A.D.) applied the codebook to the responses. Emergent themes were discussed, and codes were agreed upon by the authors (A.A.D. and A.W.K.). Twenty two codes were identified within the responses which then were further broken down into thirteen positive valency codes and nine negative valency codes. Participant responses were further grouped into two groups for quantitative analysis: Positive vs. negative/mixed valency. Interrater reliability ranged from 0.78 to 0.92 .

For quantitative analysis, binary logistic regression examined the association between the nine close-ended Likert-scale variables and valency groups (Positive $=1$, Mixed/ Negative $=0$ ). Analysis was performed using IBM SPSS Statistics version 26 [27].

\section{Results}

Table 1 displays the frequencies of the study variables. $32.5 \%$ of counselors reported that telephone counseling addressed clients' anxiety and depression to a lesser extent compared to in-person counseling. $45.9 \%$ of counselors reported that telephone counseling addressed anger issues to a lesser extent, and $27.5 \%$ of counselors reported that telephone counseling addressed their clients' substance use and recovery to a lesser extent. In terms of therapeutic relationship variables, $21.4 \%$ of counselors reported that telephone counseling was less comfortable compared to in-person counseling, 31\% reported that telephone counseling was less convenient, and $9.5 \%$ reported that their relationship with their client has worsened during telephone counseling. Overall, 69.0\% of counselors were either somewhat or very satisfied with telephone counseling.

Table 2 displays the results of logistic regression, with group membership in the valency variable as the dependent variable (positive $=1, \mathrm{mixed} /$ negative $=0$ ). The following significant associations were observed: (1) A unit increase in substance use recovery score was associated with 5.61 times increased odds of being in the positive valency group $(p=0.025)$. (2) A unit increase in recovery score was associated with 4.36 times increased odds of being in the positive valency group $(p=0.036)$. (3) A unit increase in comfort score was associated with 5.38 times increased odds of being in the positive valency group $(p=0.049)$. (4) A unit increase in convenience score was associated with 8.52 times increased odds of being in the positive valency group $(p=0.028)$. (5) A unit increase in relationship with patients score was associated with 4.81 times increased odds of being in the positive valency group ( $p=0.037)$. (6) A unit increase in overall satisfaction score was associated with 4.68 times increased odds of being in the positive valency group $(p=0.022)$. 
Table 1. Frequencies for Anxiety, Depression, Anger, Substance, Recovery, Comfort, Convenience, Relationship with Patients, and Overall Satisfaction.

\begin{tabular}{ccccc}
\hline Predictor & $\boldsymbol{n}$ & Less & The Same & More \\
\hline Anxiety & 40 & $13(32.5)$ & $18(45.0)$ & $9(22.5)$ \\
Depression & 40 & $13(32.5)$ & $23(57.5)$ & $4(10.0)$ \\
Anger & 37 & $17(45.9)$ & $16(43.2)$ & $4(10.8)$ \\
Substance & 40 & $11(27.5)$ & $22(55.0)$ & $7(17.5)$ \\
Recovery & 40 & $11(27.5)$ & $21(52.5)$ & $8(20.0)$ \\
Comfort & 42 & $9(21.4)$ & $8(19.0)$ & $5(11.9)$ \\
Convenience & 42 & $13(31.0)$ & $25(59.5)$ & $21(50.0)$ \\
Relationship with Patients & 42 & $4(9.5)$ & Neither & Somewhat/Very Satisfied \\
\hline Overall Satisfaction with & \multirow{2}{*}{ Very Dissatisfied/Dissatisfied } & $5(19.0)$ & $29(69.0)$ \\
Telephone Counseling & & \multirow{2}{*}{ (11.9) } & \\
\hline
\end{tabular}

Note. Data expressed as $n(\%)$.

Table 2. Logistic regression results comparing study variables with valency (Positive $=1$, Mixed $/$ Negative $=0$ ).

\begin{tabular}{|c|c|c|c|c|c|c|c|c|}
\hline Predictor & $\mathbf{M} \pm \mathbf{S D}$ & B & $\mathrm{SE}$ & Wald & $d f$ & $\bar{p}$ & $\operatorname{Exp}(B)$ & $95 \%$ CI of $\operatorname{Exp}(B)$ \\
\hline Anxiety & & 0.310 & 0.544 & 0.325 & 1 & 0.569 & 1.363 & $(0.470,3.955)$ \\
\hline $\begin{array}{c}\text { Positive }(n=8) \\
\text { Mixed /Negative }(n=30)\end{array}$ & $\begin{array}{l}2.00 \pm 0.76 \\
1.83 \pm .75\end{array}$ & & & & & & & \\
\hline Depression & & 0.499 & 0.678 & 0.541 & 1 & 0.462 & 1.646 & $(0.436,6.218)$ \\
\hline $\begin{array}{c}\text { Positive }(n=8) \\
\text { Mixed/Negative }(n=30)\end{array}$ & $\begin{array}{l}1.88 \pm 0.64 \\
1.70 \pm 0.60\end{array}$ & & & & & & & \\
\hline Anger & & 0.850 & 0.744 & 1.306 & 1 & 0.253 & 2.339 & $(0.545,10.050)$ \\
\hline $\begin{array}{c}\text { Positive }(n=6) \\
\text { Mixed/Negative }(n=29)\end{array}$ & $\begin{array}{l}1.83 \pm 0.41 \\
1.52 \pm 0.63\end{array}$ & & & & & & & \\
\hline Substance & & 1.725 & 0.768 & 5.049 & 1 & $0.025 *$ & 5.611 & $(1.246,25.255)$ \\
\hline $\begin{array}{c}\text { Positive }(n=8) \\
\text { Mixed/Negative }(n=30)\end{array}$ & $\begin{array}{l}2.38 \pm 0.74 \\
1.73 \pm 0.58\end{array}$ & & & & & & & \\
\hline Recovery & & 1.472 & 0.703 & 4.382 & 1 & $0.036 *$ & 4.360 & $(1.098,17.306)$ \\
\hline $\begin{array}{c}\text { Positive }(n=8) \\
\text { Mixed/Negative }(n=30)\end{array}$ & $\begin{array}{l}2.38 \pm 0.74 \\
1.77 \pm 0.63\end{array}$ & & & & & & & \\
\hline Comfort & & 1.683 & 0.859 & 3.845 & 1 & $0.049 *$ & 5.384 & $(1.001,28.971)$ \\
\hline $\begin{array}{c}\text { Positive }(n=9) \\
\text { Mixed/Negative }(n=30)\end{array}$ & $\begin{array}{l}2.22 \pm 0.44 \\
1.77 \pm 0.57\end{array}$ & & & & & & & \\
\hline Convenience & & 2.143 & 0.973 & 4.854 & 1 & $0.028 *$ & 8.523 & $(1.267,57.366)$ \\
\hline $\begin{array}{c}\text { Positive }(n=9) \\
\text { Mixed/Negative }(n=30)\end{array}$ & $\begin{array}{l}2.89 \pm 0.33 \\
1.90 \pm 0.88\end{array}$ & & & & & & & \\
\hline Relationship with Patients & & 1.571 & 0.754 & 4.339 & 1 & $0.037 *$ & 4.812 & $(1.097,21.105)$ \\
\hline $\begin{array}{c}\text { Positive }(n=9) \\
\text { Mixed/Negative }(n=30)\end{array}$ & $\begin{array}{l}2.56 \pm 0.53 \\
2.07 \pm 0.58\end{array}$ & & & & & & & \\
\hline Overall Satisfaction & & 1.543 & 0.672 & 5.269 & 1 & $0.022 *$ & 4.677 & $(1.253,17.457)$ \\
\hline $\begin{array}{c}\text { Positive }(n=9) \\
\text { Mixed /Negative }(n=30)\end{array}$ & $\begin{array}{l}4.44 \pm 0.53 \\
3.47 \pm 1.07\end{array}$ & & & & & & & \\
\hline
\end{tabular}

Note. * represents statistical significance.

Table 3 lists an example quote from counselors that corresponds to their coded response. Figures 1 and 2 illustrate the frequencies of the positive and negative valence themes and their codes, respectively. 
Table 3. Examples of quotes for coded responses.

\begin{tabular}{|c|c|}
\hline Example Quote & Name of Code \\
\hline \multicolumn{2}{|l|}{ Positive Valency Theme } \\
\hline More convenient as patients who are typically rushed to dose and leave (because of transportation or whatnot) & Convenience \\
\hline I think some of the patients are better able to express themselves without having the feeling of being stared at or judged in some way in an office setting. & Facilitates Conversations \\
\hline $\begin{array}{r}\text { It is easier for patients who work early or receive rides to the clinic to complete sessions, as there is more flexibility. Patients seem to be more engaged in } \\
\text { sessions because they are not feeling rushed. }\end{array}$ & Good for Work Schedule \\
\hline Patients are more comfortable with phone sessions and availability is better. & Greater Availability \\
\hline I get more compliance with sessions with some patients/clients. & Greater Compliance \\
\hline$i$ am able to coordinate session times with more flexibility throughout the day rather than being dependent on the dosing hour window & Greater Flexibility \\
\hline $\begin{array}{l}\text { Keeping in touch with patients when they are outside the clinic has helped a lot of patients who have little/no supports otherwise. I feel that my rapport with } \\
\qquad \begin{array}{l}\text { my clients has increased substantially over the past several months due to telephonic counseling. }\end{array}\end{array}$ & Improved Therapeutic Relationship \\
\hline $\begin{array}{l}\text {... I've also had the opportunity to touch base with my patients more frequently since we're not not constrained to dosing schedules (Ex. maybe only in the } \\
\text { clinic 2-4 times per month) and we don't have to juggle multiple patients waiting to be seen when they come to the clinic. }\end{array}$ & Increased Access to Client \\
\hline Patients are more engaged in phone sessions and are not in a rush to end session. & Increased Patient Engagement \\
\hline $\begin{array}{c}\text { Tele-health calling is a way to contact patients and provide safe effective measure of counseling and release for our patients. Allowing them to remain at a } \\
\text { safe distance for all involved. }\end{array}$ & Increased Safety \\
\hline $\begin{array}{l}\text {... I think in the future when Covid-19 is no longer a major threat and we do face to face office visits we should keep either telephone, or Zoom individual } \\
\text { sessions also in case someone has no ride or we have a snow day etc to stop having to cancel sessions. }\end{array}$ & Technology Advocacy \\
\hline \multicolumn{2}{|l|}{ Negative Valency Theme } \\
\hline I don't think telephone counseling sessions are as valuable as face-to-face counseling. & Impersonal Experience \\
\hline $\begin{array}{c}\text { I don't mind doing telehealth sessions, but it is a lot harder to reach patient's. I feel like I am always scrambling near the end of the month to see people who } \\
\text { don't answer the phone. }\end{array}$ & Lack of Availability \\
\hline
\end{tabular}

... patients often have limited privacy, this is amplified by patients children and family member being at home more often due to COVID-19 resulting in more adults and children being at home due to loss of employment and distance learning for students ...

Lack of Privacy 
Table 3. Cont.

\section{Example Quote}

Name of Code

All services provided would have been more manageable with off site access to SMART system. Moving forward should tele counseling continue, off site access would enable counselors to complete documentation more thoroughly in order to manage their caseload more effectively. While also promoting better communication between staff.

The counselor has to be straight forward and ask are you depressed? how is your anxiety? are you using any substances? Its really the same on the phone.
phones not working, voice mail box is full, patients cannot always pay phone bill on time, patients don't always check voice mail

The counselor has to be straight forward and ask are you depressed? how is your anxiety? are you using any substances? Its really the same
phones not working, voice mail box is full, patients cannot always pay phone bill on time, patients don't always check voice mail

No Difference Lessens rapport, accountability, structure and consistency. All essential in the road to recovery and abstinence.

Patient Lack of Access to Technology

I think the conversations telephonically can be just as supportive as face to face; however some patients do not engage in phone conversations as well as in person.

Reduced Patient Engagement

It works on a level but then it does not. It was fine at first but now it is very tedious to do the phone calls

Tedious

I think overall it is harder to provide clinical care as effectively over the phone as it would be in person. Body language and facial expressions can give us a

lot of information, it can make it more difficult not having that in front of us to observe. However, given the circumstances I think it is the best alternative we have available.

Telephone Counseling Lacks Communication/Connection With Clients 


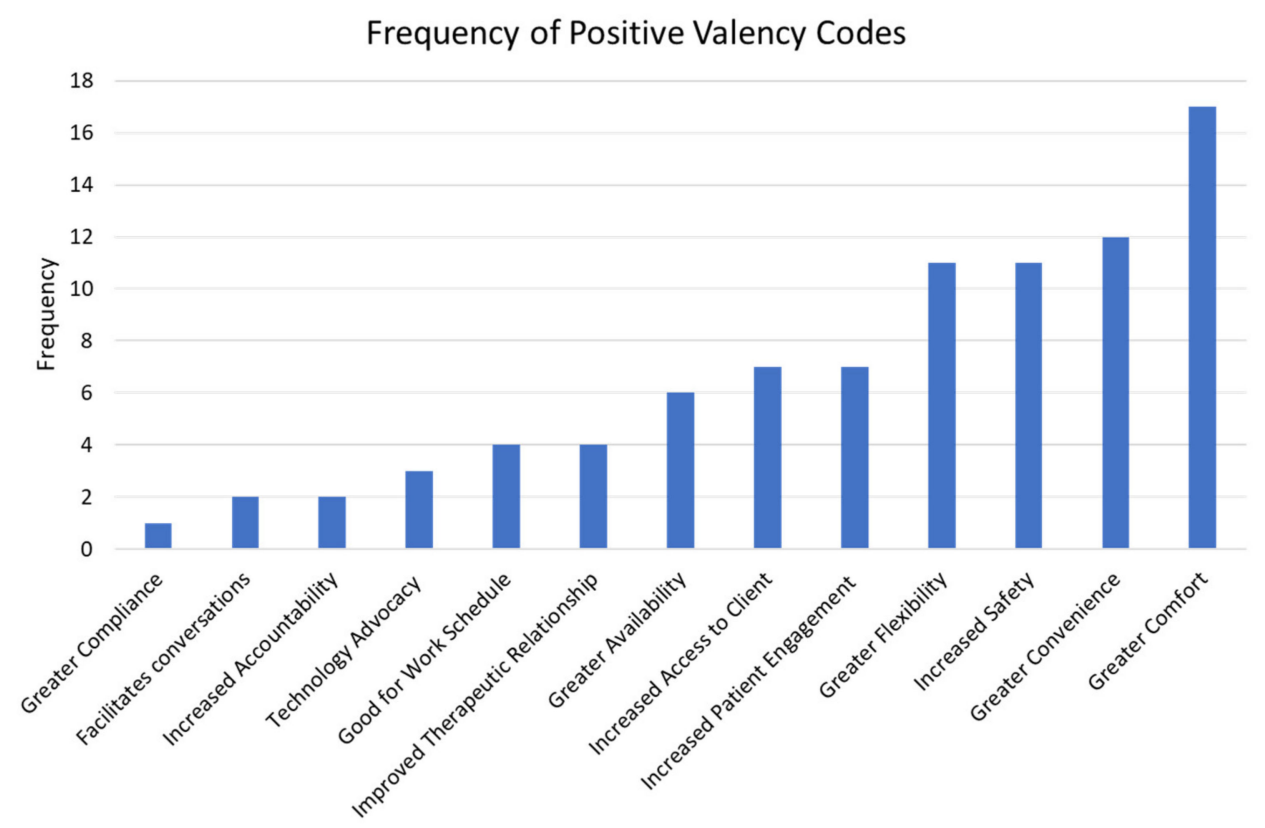

Figure 1. Frequency of positive valency codes.

\section{Frequency of Negative Valency Codes}

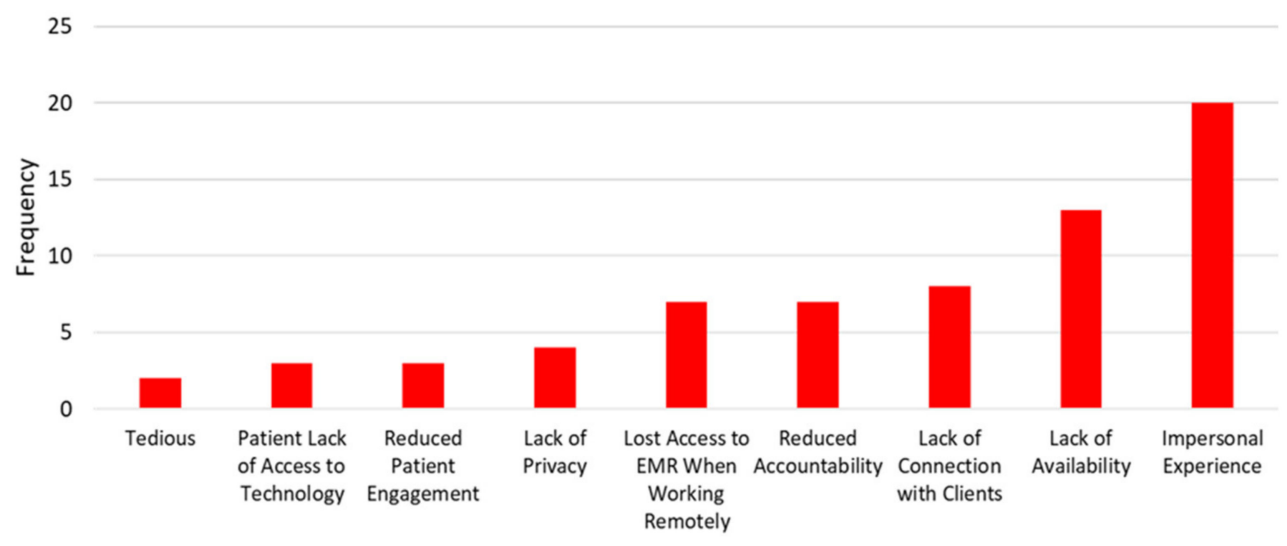

Figure 2. Frequency of negative valency codes.

\section{Discussion}

Our study provides insight into the experiences of licensed counselors who provided telephone counseling services to clients at multiple OTPs during the COVID-19 pandemic. Overall, our results fill key gaps in the literature and indicate a variety of experiences among counselors when providing OUD treatment using telephone counseling.

In general, the majority of counselors had positive experiences with telephone counseling, which was corroborated by their concurrent reports of quantitative and qualitative survey responses. Notably, the convenience of telephone counseling was significantly related to counselors' overall positive experiences; half of all counselors reported that telephone counseling was more convenient than in-person counseling. The experience of increased convenience was reiterated by counselors in their open-ended responses, where greater convenience was among the most common positive valency codes. In qualitative responses, counselors reported having greater access to their clients, more flexibility, and improved work schedules, each of which could lead to an increased sense of convenience. 
These findings are consistent with the results of a recent study, which found that both clients and counselors perceive telehealth as convenient [28,29].

Of note, counselors also stated that they believe telephone counseling to be convenient for their clients. Past research has found that inconvenient, in-person appointments are a perceived barrier to clients' engagement and retention in traditional, in-person counseling [30]. For example, even clients who reside within five miles of a clinic may experience challenges getting to their appointments without a car or have adequate access to public transportation [31]. By comparison, telephone counseling sessions can be completed from home or virtually anywhere, reducing the cost and time of travel to and from the clinic and addressing potential transportation barriers. Counselors appreciated that they had improved access to their clients and some noted that there seemed to be greater client engagement, accountability, and compliance.

Some counselors noted improvements in their therapeutic relationship with their clients after transitioning to a telephone counseling platform. Moreover, counselors also described relational processes, such as increases in comfort level and improved facilitation of conversations, that have previously been positively linked to better therapeutic relationships [31]. In future research, counselor comfort and perceived conversational flow might be studied as potential moderators of the relationship between counseling modality and the quality of the counseling relationship. Past studies have identified the therapeutic relationship as a common factor significantly predictive of client retention and treatment outcomes in counseling [32,33]. While some research found that counselor ratings of the therapeutic relationship were more strongly related to substance use outcomes than clients ${ }^{\prime}$ ratings, other researchers have found mixed results [32,34,35]. Thus, it is important to consider multiple perspectives to best understand how the virtual therapeutic experience may relate to client retention, engagement, and treatment outcomes. More attention may be needed to better understand relational processes amongst the majority of counselors who indicated that there was no difference in the therapeutic relationship for telephone counseling versus in-person sessions.

The most common negative valency code from the qualitative responses was an impersonal experience. The inability to build rapport or observe nonverbal cues has been frequently identified as a barrier to telemedicine [36]. Such barriers may also limit the discussion of sensitive topics like depression, anxiety, and anger. This finding is consistent with another study examining mental health providers' experiences with COVID19 perpetuated telehealth implementation [21]. Future research should explore ways of addressing this issue, such as by using a hybrid in-person/telehealth approach. In addition, our results suggest that telehealth-based approaches should be mindful of logistical barriers to implementation. For example, the counselors in our study experienced issues with offsite access to the electronic medical record system, with some citing issues with patients access to appropriate technology to complete sessions virtually. Hence, training and support are necessary for providers (and possibly patients) to properly adapt to a virtual environment [37].

To our knowledge, there have been no other studies that reported counselor perceptions to telephone counseling implementation in substance use treatment programs. Our study examined only telephonic versions of telehealth services, whereas other studies have observed telehealth implementation of videoconferencing platforms. When provided video platforms, counselors may adapt to telemedicine more favorably, and mental health and substance use clinics have reported benefits to the continuity of patient care, both of which align with the findings of our study $[37,38]$.

There were several limitations in our study. In terms of providers, we only collected survey data from OTP counselors (and did not include prescribers such as physicians), Due to our cross-sectional design, we were unable to assess changes in counselor perspectives (e.g., it is unclear if fatigue with the pandemic impacted perspectives towards telehealth counseling). We also did not assess the counselors' attitudes and acceptability of working remotely, which may have confounded their responses. In addition, it is unclear if the 
quality of therapeutic alliance between counselors and their patients affected counselors' responses; future research should examine the impact of therapeutic alliance on counselors' perspectives toward telehealth service provision. Lastly, our study sample was geographically limited to Northeastern USA, and results may not be generalizable to other regions and countries.

\section{Conclusions}

The rapid transition of counseling to telehealth platforms has raised the question of whether telemedicine, such as telephone counseling, should be further incorporated into post-pandemic healthcare services and the best practices for implementation. The success and sustainability of a telehealth program will be highly dependent on counselor buy-in. Prior to the onset of the pandemic and the rapid implementation of telehealth treatment, knowledge on the effectiveness of virtual counseling compared to face-to-face office visits was limited. Our findings suggest that further research with counselors is needed to identify the key elements of effective integration of telephone/virtual counseling with traditional in-person treatment approaches in the post-pandemic era.

Author Contributions: Conceptualization, A.W.K., M.R.W., A.A.D. and R.M.; methodology, A.W.K.; software, A.H.; validation, R.M.; formal analysis, A.W.K.; investigation, A.W.K., M.R.W., A.H., C.D., R.M.; resources, L.H., R.M.; data curation, M.R.W., A.H., C.D.; writing—original draft preparation and revisions, A.W.K., A.A.D., M.R.W., A.H., C.D., L.H., R.M.; supervision, L.H., R.M.; project administration, M.R.W., L.H., R.M.; funding acquisition, R.M. All authors have read and agreed to the published version of the manuscript.

Funding: This research was funded by NIH U01 DA050442-01.

Institutional Review Board Statement: The CODAC research oversight committee reviewed and approved the project.

Informed Consent Statement: Informed consent was obtained from all subjects involved in the study.

Data Availability Statement: The data presented in this study are available on request from the corresponding author. The data are not publicly available due to privacy and ethical considerations.

Conflicts of Interest: The authors declare no conflict of interest. The funders had no role in the design of the study; in the collection, analyses, or interpretation of data; in the writing of the manuscript, or in the decision to publish the results.

\section{References}

1. American Medical Association. Issue Brief: Reports of Increases in Opioid-and Other Drug-Related Overdose and Other Concerns during COVID Pandemic. AMA Advocacy Resource Center Updated. 2020: 2020-2010. Available online: http:/ /www.asapnys.org/wp-content/uploads/2020/07/Issue-brief_-Reports-of-increases-in-opioid-related-overdose-andother-concerns-during-COVID-pandemic.pdf (accessed on 1 May 2021).

2. Holland, K.M.; Jones, C.; Vivolo-Kantor, A.M.; Idaikkadar, N.; Zwald, M.; Hoots, B.; Yard, E.; D’Inverno, A.; Swedo, E.; Chen, M.S.; et al. Trends in US Emergency Department Visits for Mental Health, Overdose, and Violence Outcomes before and during the COVID-19 Pandemic. JAMA Psychiatry 2021, 78, 372. [CrossRef] [PubMed]

3. Livingston, N.A.; Ameral, V.; Banducci, A.N.; Weisberg, R.B. Unprecedented need and recommendations for harnessing data to guide future policy and practice for opioid use disorder treatment following COVID-19. J. Subst. Abus. Treat. 2021, 122, 108222. [CrossRef]

4. Drug Enforcement Administration. Implementation of the Ryan Haight Online Pharmacy Consumer Protection Act of 2008. Interim final rule with request for comments. Fed. Regist. 2009, 4, 15595-15625.

5. Bliley, T.H.R. 2634-Drug Addiction Treatment Act of 2000. 2000. Available online: https://www.congress.gov/bill/106thcongress/house-bill/2634 (accessed on 1 May 2021).

6. Electronic Code of Federal Regulations. 42CFR Part 8. 2021. Available online: https://www.ecfr.gov/cgi-bin/retrieveECFR?gp= $3 \& S I D=7282616 a c 574225 f 795 d 5849935$ efc45\&ty=HTML\&h=L\&n=pt42.1.8\&r=PAR (accessed on 1 May 2021).

7. Koonin, L.M.; Hoots, B.; Tsang, C.A.; Leroy, Z.; Farris, K.; Jolly, B.; Antall, P.; McCabe, B.; Zelis, C.B.; Tong, I.; et al. Trends in the use of telehealth during the emergence of the COVID-19 pandemic-United States, January-March 2020. Morb. Mortal. Wkly. Rep. 2020, 69, 1595. [CrossRef] [PubMed] 
8. Hansel, T.C.; Saltzman, L.Y.; Bordnick, P.S. Behavioral Health and Response for COVID-19. Disaster Med. Public Health Prep. 2020, 14, 670-676. [CrossRef] [PubMed]

9. Pinals, D.A.; Hepburn, B.; Parks, J.; Stephenson, A.H. The Behavioral Health System and Its Response to COVID-19: A Snapshot Perspective. Psychiatr. Serv. 2020, 71, 1070-1074. [CrossRef] [PubMed]

10. Wright, J.H.; Caudill, R. Remote Treatment Delivery in Response to the COVID-19 Pandemic. Psychother. Psychosom. 2020, 89, 130-132. [CrossRef]

11. Backhaus, A.; Agha, Z.; Maglione, M.L.; Repp, A.; Ross, B.; Zuest, D.; Rice-Thorp, N.M.; Lohr, J.; Thorp, S.R. Videoconferencing psychotherapy: A systematic review. Psychol. Serv. 2012, 9, 111-131. [CrossRef]

12. Bashshur, R.L.; Shannon, G.W.; Bashshur, N.; Yellowlees, P.M. The Empirical Evidence for Telemedicine Interventions in Mental Disorders. Telemed. E-Health 2016, 22, 87-113. [CrossRef]

13. Batastini, A.B.; Jones, A.C.T.; Lester, M.E.; Davis, R.M. Initiation of a multidisciplinary telemental health clinic for rural justiceinvolved populations: Rationale, recommendations, and lessons learned. J. Community Psychol. 2020, 48, 2156-2173. [CrossRef]

14. Kruse, C.S.; Krowski, N.; Rodriguez, B.; Tran, L.; Vela, J.; Brooks, M. Telehealth and patient satisfaction: A systematic review and narrative analysis. BMJ Open 2017, 7, e016242. [CrossRef] [PubMed]

15. Huskamp, H.A.; Busch, A.B.; Souza, J.; Uscher-Pines, L.; Rose, S.; Wilcock, A.; Landon, B.E.; Mehrotra, A. How is telemedicine being used in opioid and other substance use disorder treat-ment? Health Aff. 2018, 37, 1940-1947. [CrossRef] [PubMed]

16. Lin, L.; Casteel, D.; Shigekawa, E.; Weyrich, M.S.; Roby, D.H.; McMenamin, S.B. Telemedicine-delivered treatment interventions for substance use disorders: A systematic review. J. Subst. Abus. Treat. 2019, 101, 38-49. [CrossRef] [PubMed]

17. Tarp, K.; Bojesen, A.B.; Mejldal, A.; Nielsen, A.S. Effectiveness of optional videoconferencing-based treatment of alcohol use dis-orders: Randomized controlled trial. JMIR Ment. Health 2017, 4, e38. [CrossRef]

18. King, V.L.; Brooner, R.K.; Peirce, J.M.; Kolodner, K.; Kidorf, M.S. A randomized trial of Web-based videoconferencing for substance abuse counseling. J. Subst. Abus. Treat. 2014, 46, 36-42. [CrossRef]

19. Eibl, J.K.; Gauthier, G.; Pellegrini, D.; Daiter, J.; Varenbut, M.; Hogenbirk, J.C.; Marsh, D.C. The effectiveness of telemedicinedelivered opioid agonist therapy in a supervised clinical setting. Drug Alcohol Depend. 2017, 176, 133-138. [CrossRef]

20. Arnow, B.A.; Steidtmann, D.; Blasey, C.; Manber, R.; Constantino, M.J.; Klein, D.N.; Markowitz, J.C.; Rothbaum, B.O.; Thase, M.E.; Fisher, A.J.; et al. The relationship between the therapeutic alliance and treatment outcome in two distinct psychotherapies for chronic depression. J. Consult. Clin. Psychol. 2013, 81, 627-638. [CrossRef]

21. Sugarman, D.E.; Horvitz, L.E.; Greenfield, S.F.; Busch, A.B. Clinicians' Perceptions of Rapid Scale-up of Telehealth Services in Outpatient Mental Health Treatment. Telemed. E-Health 2021. [CrossRef]

22. Connolly, S.L.; Miller, C.J.; Lindsay, J.A.; Bauer, M.S. A systematic review of providers' attitudes toward telemental health via videoconferencing. Clin. Psychol. Sci. Pract. 2020, 27. [CrossRef]

23. Thomas, N.; McDonald, C.; De Boer, K.; Brand, R.M.; Nedeljkovic, M.; Seabrook, L. Review of the current empirical literature on using videoconferencing to deliver individual psychotherapies to adults with mental health problems. Psychol. Psychother. Theory Res. Pract. 2021. [CrossRef]

24. Nittari, G.; Khuman, R.; Baldoni, S.; Pallotta, G.; Battineni, G.; Sirignano, A.; Amenta, F.; Ricci, G. Telemedicine Practice: Review of the Current Ethical and Legal Challenges. Telemed. E-Health 2020, 26, 1427-1437. [CrossRef]

25. Gilmore, A.K.; Ward-Ciesielski, E.F. Perceived risks and use of psychotherapy via telemedicine for patients at risk for suicide. J. Telemed. Telecare 2017, 25, 59-63. [CrossRef]

26. Creswell, J.W.; Clark, V.L.P. Designing and Conducting Mixed Methods Research; Sage Publications: Thousand Oaks, CA, USA, 2017.

27. IBM SPSS Statistics for Windows, [Computer Program], Version Version 26.0; IMB Corp.: Armonk, NY, USA, 2019.

28. Donelan, K.; Barreto, E.A.; Sossong, S.; Michael, C.; Estrada, J.J.; Cohen, A.B.; Wozniak, J.; Schwamm, L.H. Patient and clinician experiences with telehealth for patient follow-up care. Am. J. Manag. Care 2019, 25, 40-44.

29. Petersen, D.; Salazar, B.; Kertz, S.J. Therapist and Treatment-Seeking Students' Perceptions of Telemental Health. J. Technol. Behav. Sci. 2019, 5, 113-120. [CrossRef]

30. Mitchell, A.J.; Selmes, T. Why don't patients attend their appointments? Maintaining engagement with psychiatric services. Adv. Psychiatr. Treat. 2007, 13, 423-434. [CrossRef]

31. Rubin, R. Using Telemedicine to Treat Opioid Use Disorder in Rural Areas. JAMA 2019, 322, 1029. [CrossRef] [PubMed]

32. Marsh, J.C.; Angell, B.; Andrews, C.M.; Curry, A. Client-Provider Relationship and Treatment Outcome: A Systematic Review of Substance Abuse, Child Welfare, and Mental Health Services Research. J. Soc. Soc. Work Res. 2012, 3, 233-267. [CrossRef]

33. Leibert, T.W.; Dunne-Bryant, A. Do Common Factors Account for Counseling Outcome? J. Couns. Dev. 2015, 93, 225-235. [CrossRef]

34. Connors, G.J.; Carroll, K.M.; DiClemente, C.C.; Longabaugh, R.; Donovan, D.M. The therapeutic alliance and its relationship to alcoholism treatment participation and outcome. J. Consult. Clin. Psychol. 1997, 65, 588-598. [CrossRef] [PubMed]

35. Dundon, W.; Pettinati, H.; Lynch, K.; Xie, H.; Varillo, K.; Makadon, C.; Oslin, D. The therapeutic alliance in medical-based interventions impacts outcome in treating alcohol dependence. Drug Alcohol Depend. 2008, 95, 230-236. [CrossRef] [PubMed]

36. Wagnild, G.; Leenknecht, C.; Zauher, J. Psychiatrists' Satisfaction with Telepsychiatry. Telemed. E-Health 2006, $12,546-551$. [CrossRef] [PubMed] 
37. Yellowlees, P.; Nakagawa, K.; Pakyurek, M.; Hanson, A.; Elder, J.; Kales, H.C. Rapid Conversion of an Outpatient Psychiatric Clinic to a 100\% Virtual Telepsychiatry Clinic in Response to COVID-19. Psychiatr. Serv. 2020, 71, 749-752. [CrossRef] [PubMed]

38. Reay, R.E.; Looi, J.C.; Keightley, P. Telehealth mental health services during COVID-19: Summary of evidence and clinical practice. Australas. Psychiatry 2020, 28, 514-516. [CrossRef] [PubMed] 